Authorship characteristics in prosthodontic literature: proliferation and internationalization. A review and analysis following a 10-year observation

Judy Chia-Chun Yuan, DDS, MS, ${ }^{a}$ Damian J. Lee, DDS, ${ }^{b}$ Kent L. Knoernschild, DMD, MS, ${ }^{c}$ Stephen D. Campbell, DDS, MMSc, ${ }^{\mathrm{d}}$ and Cortino Sukotjo, DDS, MMSc, $\mathrm{PhD}^{\mathrm{e}}$

College of Dentistry, University of Illinois at Chicago, Chicago, Ill

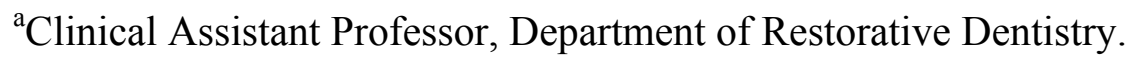

${ }^{\mathrm{b}}$ Clinical Assistant Professor, Department of Restorative Dentistry.

${ }^{c}$ Associate Professor, Director, Advanced Prosthodontics, Department of Restorative Dentistry.

${ }^{\mathrm{d}}$ Professor, Head of Restorative Dentistry, Department of Restorative Dentistry.

${ }^{\mathrm{e}}$ Assistant Professor, Department of Restorative Dentistry. 
Statement of problem. Author characteristics and the extent of dental literature authorship globalization have not been widely investigated, especially in prosthodontics.

Purpose. The purpose of this review was to examine trends in authorship characteristics in prosthodontics.

Material and methods. Articles published in The Journal of Prosthetic Dentistry (JPD), International Journal of Prosthodontics (IJP), and Journal of Prosthodontics (JP) in 1998, 2003, and 2008 were reviewed. Abstracts, letters to the editor, and book reviews were not included in the investigation. The authors' educational degrees had to be listed in the publications for the articles to be included. For each article, number of authors, degrees of all authors, academic ranks of first and last authors, and geographic origin were recorded. Descriptive and analytic analyses $(\alpha=.05)$, including a generalized linear model, Kruskall-Wallis, Mann-Whitney U, or chi-square tests, were used as appropriate.

Results. A total of 998 articles met the inclusion criteria from the 3 selected journals for the years studied. Across all 3 journals, the mean number of authors per article increased significantly from 2.9 in 1998 to 3.6 in 2008 (Kruskal-Wallis, $P<.001$ ). The mean number of authors per article increased steadily on all continents, except for Africa and Oceania. A steady increase of authors with higher degrees was observed. There was a significant increase in the proportion of senior-ranking faculty as last author over time (chi-square $=5.57, d f=1, P=.018$ ). The contributions from Asia and South America increased over time.

Conclusions. The number of authors per article, the number of authors with higher educational degrees, and the percentage of senior-ranking faculty as last author have steadily increased in the prosthodontic literature from 1998 to 2008. The trend of globalization of authorship was evident in the prosthodontic literature. 


\section{CLINICAL IMPLICATIONS}

The trend in authorship proliferation and internationalization was observed in the prosthodontic literature for the years studied. This trend may suggest broad collaboration and diverse contribution in the prosthodontic specialty. 
Many studies have evaluated trends in authorship in the biomedical field, ${ }^{1-10}$ and several reports showed a considerable increase in the proportion of multiple authors per article in prestigious medical journals over the past decades. ${ }^{1,2,4-8,11,12}$ Although some benefits of single authorship were evident, ${ }^{13}$ single authorship has become almost obsolete. ${ }^{3,8}$ The positive factors attributed to the proliferation of the multiple authorship trend included the increased complexity of the research projects, enhanced quality of the written work, division of labor, increase in collaboration, joy of working with colleagues, and professional development opportunities. $^{6,8,12,1314,15}$

Others have challenged that multi-authorship threatens the motivation of scientists, adversely affects accountability of the scientists, ${ }^{16}$ and dilutes the inherent value of authorship. ${ }^{11}$ As a result, the International Committee of Medical Journal Editors (ICMJE) has defined criteria for authorship. ${ }^{17}$ These guidelines state that the listed authors should make substantial contributions to conception and design of the work, or acquisition and interpretation of data; draft the article or revise it critically for important intellectual content; and provide approval of final version.

Increased incidence of international authorship has also become apparent. ${ }^{2,18,19,20}$ Several studies reveal an increased contribution of articles from Europe, East Asia, and Oceania, whereas publications from US authors have declined over time. ${ }^{2,18,19}$ Some consider this phenomenon to be a positive influence on research and development, and note improvement in the quality of investigations outside the US. ${ }^{19,21}$

The topic of authorship and its characteristics, along with the trend of authorship globalization in the dental literature, has not been widely investigated, especially in prosthodontics. The purpose of this study was to examine the trend of authorship in 
prosthodontics by: (1) identifying the contributing factors for authorship trend; (2) exploring the prevalence of coauthored articles; (3) reviewing the characteristics of authorship in the prosthodontic journals, including the educational degree and academic rank of authors; and (4) evaluating the geographic origins of the publications. The null hypothesis was that there would be no differences in authorship and publication contributions from various geographic origins over time.

\section{MATERIAL AND METHODS}

A hand search of 3 peer-reviewed prosthodontic journals was performed for articles published in 1998, 2003, and 2008. These periods were chosen for 2 reasons: because they represent a 10 -year observation time for comparison points and because the articles were available online. The journals were selected based on published impact factors, as well as because they are most representative of the specialty and of the prosthodontic organizations. For articles to be included in the study, the educational degrees of the authors had to be listed in the publications. The 3 journals selected for this study were: The Journal of Prosthetic Dentistry (JPD), International Journal of Prosthodontics (IJP), and Journal of Prosthodontics (JP).

Abstracts, letters to the editor, and book reviews were not included.

For each of the included articles, specific parameters were collected: number of authors, educational degrees of all authors, academic ranks of first and last authors, and geographic origin of the article. With respect to number of authors, the articles were grouped as having 1,2,3,4, or 5 or more authors, based on Rosenzweig et al. ${ }^{6}$ The categories of the educational degrees of all authors were $\mathrm{DMD} / \mathrm{DDS} / \mathrm{BDS}, \mathrm{DDS}$ and $\mathrm{MS}$, DDS and $\mathrm{PhD}, \mathrm{MS}, \mathrm{PhD}$, or other. The academic 
ranks of first and last authors were classified as student/resident, junior faculty, senior faculty, or other/unidentified. The classification of academic ranks was according to Drenth, ${ }^{1}$ with modification. Classifications were simplified from the proposed 8 categories. Instructor, lecturer, and assistant professor were grouped as junior faculty, whereas associate professor, professor, and administrative heads were classified as senior faculty. The geographic origin of the article was categorized by continents according to Rahman and Fukui ${ }^{21}$ : North America, Europe, Asia, South America, Africa, and Oceania (Australia and proximate Pacific islands). If more than one geographic origin of the study was listed, the country of the corresponding author was selected.

Data were recorded and coded into a software database (Microsoft Excel 2003; Microsoft Corp, Redmond, Wash). Statistical software (SPSS v. 17.0; SPSS, Inc, Chicago, Ill) was used for descriptive and statistical analyses. For each year, frequency and percentage were calculated for number of authors per article, academic ranks of first and last authors, and educational degrees of first, last, and all authors. The influences of various independent variables (year, journal, geographic origin) on the dependent variable (number of authors per article) were assessed using a generalized linear model $(\alpha=.05)$. Main and interaction effects of the variables were tested, and for associations with a $P$ value of less than .05 , further analyses were performed.

For bivariate analyses, the Kruskal-Wallis test and the chi-square $\left(\chi^{2}\right)$ test with Yate's continuous correction were used. The Kruskal-Wallis test assessed associations among the number of authors per article over time, across continents and across journals, associations among the number of articles across journals over time, relationship of academic ranks of first and last authors over time and across journals, and educational degrees over time. Within each year, comparison among variables was performed using the Mann-Whitney $U$ test to assess the number of authors per article by journal and geographic origin. Within each geographic region, a 
Mann-Whitney $\mathrm{U}$ test was performed to assess the differences in number of published articles by journal. The chi-square test was used to assess potential differences between the years of 1998 and 2008, based on authors' educational degrees, academic ranks, and geographic origin. All post hoc analyses were performed with $\alpha=.05$.

\section{RESULTS}

A total of 998 articles met the inclusion criteria from the 3 selected journals for the years studied. Table I shows the relationship of various factors to the number of authors per article. Each of the independent variables of year, journal, and geographic origin, as well as 2- and 3way interactions among variables, were identified as contributing factors to the number of authors per article. This justified further post hoc analysis.

The range and the mean number of authors per article by year, journal, and geographic origin are presented in Table II. Across all 3 journals, the mean number of authors per article increased significantly from 2.9 in 1998 to 3.6 to 2008 (Kruskal-Wallis, $P<.001$ ). There was a significant difference in the mean number of authors per article among the journals (KruskalWallis, $P<.001)$, and IJP $(3.7 \pm 1.7)$ had a greater mean number of authors than JP $(3.3 \pm 1.5)$ and JPD (3.1 \pm 1.3$)$. IJP had a significantly higher number of authors per article in 2003 and 2008 (Kruskal-Wallis, $P<.001$ ). With regard to geographic origins, the mean number of authors per article increased steadily from 1998 to 2008, except for articles from Africa and Oceania. There was a significant difference in the number of authors per article among all continents in 2003 (Kruskal-Wallis, $P<.001$ ) and 2008 (Kruskal-Wallis, $P<.001$ ). The proportion of authors from South America was higher compared to all other continents in 2003 and 2008. 
The proportion of single-author articles decreased over time for all journals, from $17 \%$ in 1998 to 5\% in 2008 (Fig. 1). Publications with 5 or more authors increased threefold from 1998 to 2008 .

Among all first authors, there was no significant difference in the proportion of academic ranks over the years (Fig. 2) or across the journals. In contrast, there was a significant increase in the proportion of senior-ranking faculty as last author over time $\left(\chi^{2}=5.57, d f=1, P=.018\right)$ (Fig. 2). The percentage of senior-ranking faculty as last author was consistently more than $50 \%$ over the time periods measured.

Among the first and last authors, over this time period, a steady increase in authors with higher educational degrees was observed (Fig. 3). Across all journals, 34\% of first authors and $43 \%$ of senior authors held both dental and $\mathrm{PhD}$ degrees in 2008 . Authors holding both dental and $\mathrm{PhD}$ degrees were higher in IJP $(40 \%, 44 \%, 44 \%)$ compared to JPD $(20 \%, 25 \%, 26 \%)$ and JP (9\%, 9\%, 35\%) from 1998, 2003, and 2008, respectively. There was a steady increase in joint dental and $\mathrm{PhD}$ degrees $\left(\chi^{2}=6.86, d f=1, P=.009\right)$ for first authors over time. For last authorship, from 1998 to 2008, there was a twofold increase in those holding dental and PhD degrees $\left(\chi^{2}=43.87, d f=1, P<.001\right)$. There was a slight decrease in first and last authors holding dental degree over time.

The distribution of publications by continents and educational degrees of all authors over the reported years is presented in Table III. The authors holding a $\mathrm{PhD}$ degree decreased nearly $50 \%$ for North America, whereas an increase was observed for authors from Europe, Asia, and South America, from 1998 to 2008. Of authors holding both dental and PhD degrees, representations from North America and Europe decreased from 1998 to 2008. In contrast, Asia 
and South America showed a steady increase in the number of authors holding dental and $\mathrm{PhD}$ degrees over time.

North America and Europe represented the majority of publications in the years studied, except in 2008, when Asia replaced Europe as a major contributor (Table IV). However, contributions from North America decreased significantly from 1998 to $2008\left(\chi^{2}=25.48, d f=1\right.$, $P<.001$ ), whereas publications from Asia and South America increased significantly from $12 \%$ to $28 \%\left(\chi^{2}=24.86, d f=1, P<.001\right)$ and $3 \%$ to $7 \%\left(\chi^{2}=6.55, d f=1, P=.01\right)$ during the same period, respectively (Table IV). From 1998 to 2008, North America accounted for more than half of the publications in the JP and JPD (Mann-Whitney $\mathrm{U}, P<.001$ ), and Europe had similar representation in the IJP (Mann-Whitney $\mathrm{U}, P<.001$ ).

\section{DISCUSSION}

The hypothesis that there would be no differences in authorship and publication contributions from various geographic origins was rejected. This study demonstrated that multiple authorship has become more prevalent in the prosthodontic literature. The number of authors per article increased significantly over time (Fig. 1). In contrast, the proportion of articles by a single author has decreased dramatically over time. These trends are similar to previous trends reported for the medical literature. ${ }^{1-8,11,12}$

The proliferation of authorship has been documented since the 1930 s. $^{3}$ Podolsky et $\mathrm{al}^{5}$ noted an increase in the number of authors per article from 1.1 in 1972 to 2.6 in 1981 . Weeks et $\mathrm{al}^{8}$ found the average number of authors per article increased from 4.5 in 1980 to 6.9 in 2000 , in 4 medical journals. Others have reported a steady increase in the proportion of articles with 6 or 
more authors. ${ }^{3,6,8,10}$ The mean number of authors per article in the selected prosthodontic literature was observed to be less than in the medical publications over the years examined.

There are many driving forces behind authorship proliferation, such as academic advancement, collaborative team approach, and complexity of research. A recent study reported an increase in both authorship and collaboration. ${ }^{6}$ Publication in peer-reviewed journals is an objective measure of academic productivity. ${ }^{14}$ Consequently, it contributes to the promotion and tenure process for faculty members. ${ }^{15}$ Therefore, the proliferation of authorship may be due to the academic advancement process. ${ }^{9}$ Others have suggested that multinational clinical research and articles published in high impact factor journals may contribute to this phenomenon. ${ }^{2,3,10,12}$ However, the trend in authorship proliferation should be viewed with caution. ${ }^{17}$ The International Committee of Medical Journal Editors (ICMJE) has provided some guidelines for authorship. Some authors may have been included without meeting these requirements. Others have reported the prevalence of honorary and ghost authorship. ${ }^{22}$ This current study did not assess the trends regarding authorship and collaboration, funding, or the nature of the published articles. Therefore, it is not possible to conclude if the proliferation of authorship in the prosthodontic literature was driven by any of these factors. Additional investigation is warranted to further evaluate the trends and causes of authorship proliferation in prosthodontic publications.

Different authorship profiles across individual journals were observed. The IJP had a significantly higher number of authors per article, compared to the JPD and JP, in 2003 and 2008. Weeks et $\mathrm{al}^{8}$ suggested that the differences in authorship profiles might be the preference of editors, or may be random. For the selected journals in this study, The Journal of Prosthetic Dentistry requires the primary author to justify the contributions of all of the listed authors if the author number exceeds 4 , whereas the other journals do not have restrictions on authorship. This 
may be a reason that the JPD had a relatively lower mean number of authors per article, compared to the JP and IJP, in 2008.

A steady increase in authors with higher educational degrees was observed, while an increase in senior-ranking faculty and a great surge in dental and $\mathrm{PhD}$ degrees for last authorship were noted. This observation may confirm a trend shown in previous studies ${ }^{1,7}$ : that seniorranking faculty now usually hold higher educational degrees. In addition, with more faculty obtaining advanced training, it could be construed that there is more interest and proficiency in performing research. This observation may point to a promising future for the specialty. This may also indicate that individuals who have achieved academic stature are still capable of publication because they have established themselves and thereby continue to receive the funding that ensures their future as investigators. In contrast, younger faculty members may have less time to participate in research due to heavier teaching loads. Few younger faculty members may be provided with adequate, dedicated time for research investigations.

Greater globalization of authorship in the prosthodontic specialty has occurred over the years. In the current study, it was observed that the contributions from Asia and South America had a multifold increase, and this mirrors the trends in internationalization in the medical literature. ${ }^{2,3,18,19}$ Publications from the rest of the globe represent the positive impact that prosthodontics has on the advancement of knowledge. Diverse contributions to the literature, international collaboration, and broadened readership are outcomes of increased globalization which may subsequently be measured through the impact factors and reputations of journals. ${ }^{3,19,20}$

The current study has identified some notable findings regarding geographic origin and its association with authorship. First, representation from Europe has been consistently higher in 
the IJP over the years. The IJP is an international journal; therefore, it is conceivable that more international articles were submitted and consequently published. US authors tend to be represented in a higher proportion in US-based journals, and less in foreign journals. ${ }^{18}$ Secondly, authors from Europe, Asia, and South America have shown a significant increase in the number of PhD degrees. Authors from Asia and South America have demonstrated an increasing trend in dual degrees (dental and $\mathrm{PhD}$ degrees). Some attribute this to the proliferation of senior faculty members, such as chairpersons and professors, these individuals tend to hold higher educational degrees. ${ }^{1,7}$ It may be speculated that more authors have received advanced education and research training over the years; thus, more authors with advanced degrees are emerging in publications. Lastly, the contributions from Europe and South America had a higher number of authors per article, compared to other continents over the same period. This could be the nature of the article, complexity of the research, or culture of authorship. ${ }^{8}$ It is not possible to provide any definitive conclusion, as this study did not evaluate these factors.

There are several limitations in the interpretation of the findings. This study only reviewed the 3 peer-reviewed prosthodontic journals published in North America. Therefore, the findings of the current study may limit the generalization of the results to other journals, specialties, and dental literature as a whole. It is possible that US-based authors are publishing in a variety of other journals as well. Furthermore, this study did not evaluate the casual or inferential relationship between some potential variables, such as collaboration and funding sources, and multiple authorship. This information may be important to identify more detail, and to learn the reasons for the increase in multiple authorship in the dental literature.

\section{CONCLUSIONS}


Within the limitations of this study, the following conclusions were drawn:

1. The number of authors per article in the prosthodontic literature has steadily and significantly increased from 1998 to 2008 , from 2.9 to 3.6.

2. The number of authors with higher educational degrees has increased, especially those authors from Europe, Asia, and South America.

3. The percentage of senior-ranking faculty as last author was consistently higher than $50 \%$ and has increased over time.

4. The trend in globalization of authorship was evident in the prosthodontic literature; in particular, an increase in authors from Asia and South America was seen. 


\section{REFERENCES}

1. Drenth JP. Multiple authorship: the contribution of senior authors. JAMA 1998;280:219-21. 2. Kanavakis G, Spinos P, Polychronopoulou A, Eliades T, Papadopoulos MA, Athanasiou AE. Orthodontic journals with impact factors in perspective: trends in the types of articles and authorship characteristics. Am J Orthod Dentofacial Orthop 2006;130:516-22.

3. Modi P, Hassan A, Teng CJ, Chitwood WR Jr. "How many cardiac surgeons does it take to write a research article?": seventy years of authorship proliferation and internationalization in the cardiothoracic surgical literature. J Thorac Cardiovasc Surg 2008;136:4-6.

4. Papatheodorou SI, Trikalinos TA, Ioannidis JP. Inflated numbers of authors over time have not been just due to increasing research complexity. J Clin Epidemiol 2008;61:546-51.

5. Podolsky SM, Gold I, Kuhn M, Baraff LJ. Research topics, author's specialty, and funding sources of articles published in an emergency medicine journal. Ann Emerg Med 1984;13:42931.

6. Rosenzweig JS, Van Deusen SK, Okpara O, Datillo PA, Briggs WM, Birkhahn RH. Authorship, collaboration, and predictors of extramural funding in the emergency medicine literature. Am J Emerg Med 2008;26:5-9.

7. Shulkin DJ, Goin JE, Rennie D. Patterns of authorship among chairmen of departments of medicine. Acad Med 1993;68:688-92.

8. Weeks WB, Wallace AE, Kimberly BC. Changes in authorship patterns in prestigious US medical journals. Soc Sci Med 2004;59:1949-54.

9. Levsky ME, Rosin A, Coon TP, Enslow WL, Miller MA. A descriptive analysis of authorship within medical journals, 1995-2005. South Med J 2007:100:371-5. 
10. Shaban S, Aw TC. Trend towards multiple authorship in occupational medicine journals. J Occup Med Toxicol 2009;4:3.

11. Shapiro DW, Wenger NS, Shapiro MF. The contributions of authors to multiauthored biomedical research papers. JAMA 1994;271:438-42.

12. Figg WD, Dunn L, Liewehr DJ, Steinberg SM, Thurman PW, Barrett JC, et al. Scientific collaboration results in higher citation rates of published articles. Pharmacotherapy 2006;26:75967.

13. Moore MT, Griffin BW. Identification of factors that influence authorship name placement and decisions to collaborate in peer-reviewed, education-related publications. Stud Educ Eval 2006;32:125-35.

14. Lundberg GD. Publication and promotion. Writing is all. Lancet 1998;352:898.

15. Masella RS, Thompson TJ. Dental education and evidence-based educational best practices: bridging the great divide. J Dent Educ 2004;68:1266-71.

16. Wray KB. Scientific authorship in the age of collaborative research. Stud Hist Phil Sci 2006;37:505-14.

17. International Committee of Medical Journal Editors. Uniform requirements for manuscripts submitted to biomedical journals: writing and editing for biomedical publication (updated October 2008). Available at: http://www.icmje.org. Accessed March 22, 2010.

18. Matson ML, Matso JL, Lott JD, Logan JR. Representation of international authorship across prominent journals in the field of mental retardation. Res Dev Disabil 2002;23:293-6.

19. Cappell MS, Davis M. A significant decline in the American domination of research in gastroenterology with increasing globalization from 1980 to 2005: an analysis of American authorship among 8,251 articles. Am J Gastroenterol 2008;103:1065-74. 
20. Durani P, Rimouche S, Ross G. 'How many plastic surgeons does it take to write a research article?' - Authorship proliferation in and internationalisation of the plastic surgery literature. $\mathrm{J}$ Plast Reconstr Aesthet Surg 2007;60:956-7.

21. Rahman M, Fukui T. Biomedical publication--global profile and trend. Public Health $2003 ; 117: 274-80$.

22. Mowatt G, Shirran L, Grimshaw JM, Rennie D, Flanagin A, Yank V, et al. Prevalence of honorary and ghost authorship in Cochrane reviews. JAMA 2002;287:2769-71.

Corresponding author:

Dr Cortino Sukotjo

Department of Restorative Dentistry

University of Illinois at Chicago

College of Dentistry (MC 555), Rm 365B

801 South Paulina St

Chicago, IL 60612-7211

Fax: 312-996-3535

E-mail: csukotjo@uic.edu 
Table I. Summary of generalized linear model for testing main and interaction effects for independent variables as contributing factors to number of authors per article

\begin{tabular}{|ll|}
\hline Independent Variables & $P$ \\
Year & $.001^{*}$ \\
Journal & $.016^{*}$ \\
Geographic origin & $<.001^{*}$ \\
Year $\times$ journal & $.009^{*}$ \\
Year $\times$ geographic origin & $<.001^{*}$ \\
Journal $\times$ geographic origin & $<.001^{*}$ \\
Year $\times$ journal $\times$ geographic origin & $<.001^{*}$ \\
\hline
\end{tabular}

*Model tested main effects of year, journal, and geographic origins; and interaction effects between year and journal, between year and geographic origin, and between journal and geographic origin, and among year, journal, and geographic origins, respectively. Differences are significant for $P<.05$. 
Table II. Number, mean, standard deviation, and range of authors per article, by year, journal, and geographic origin

\begin{tabular}{|c|c|c|c|c|c|c|c|c|c|c|c|c|c|}
\hline \multicolumn{14}{|l|}{ Year } \\
\hline \multirow{3}{*}{ Range } & \multicolumn{4}{|c|}{$1998(n=334)$} & \multicolumn{4}{|c|}{$2003(n=345)$} & \multicolumn{5}{|c|}{$2008(n=319)$} \\
\hline & $1-11$ & & & & $1-8$ & & & & $1-8$ & & & & \\
\hline & JP & JPD & IJP & Total & JP & JPD & IJP & Total & JP & JPD & IJP & Total & $P$ \\
\hline $\begin{array}{l}\text { Geographic } \\
\text { Origin }\end{array}$ & $\begin{array}{l}\text { Mean } \\
\text { (SD) }\end{array}$ & & & & $\begin{array}{l}\text { Mean } \\
\text { (SD) }\end{array}$ & & & & $\begin{array}{l}\text { Mean } \\
\text { (SD) }\end{array}$ & & & & \\
\hline North America & $\begin{array}{l}3.0 \\
(1.2)\end{array}$ & $\begin{array}{l}3.0 \\
(1.5)\end{array}$ & $\begin{array}{l}2.2 \\
(1.2)\end{array}$ & $\begin{array}{l}2.9 \\
(1.4)\end{array}$ & $\begin{array}{l}2.5 \\
(1.6)\end{array}$ & $\begin{array}{l}3.0 \\
(1.3)\end{array}$ & $\begin{array}{l}3.9 \\
(1.8)\end{array}$ & $\begin{array}{l}3.0 \\
(1.4)^{\mathrm{a}}\end{array}$ & $\begin{array}{l}3.4 \\
(1.1)\end{array}$ & $\begin{array}{l}3.2 \\
(1.5)\end{array}$ & $\begin{array}{l}4.0 \\
(1.5)\end{array}$ & $\begin{array}{l}3.3 \\
(1.4)^{\mathrm{a}}\end{array}$ & \\
\hline Europe & $\begin{array}{l}2.5 \\
(2.1)\end{array}$ & $\begin{array}{l}2.9 \\
(1.2)\end{array}$ & $\begin{array}{l}3.5 \\
(2.1)\end{array}$ & $\begin{array}{l}3.1 \\
(1.6)\end{array}$ & $\begin{array}{l}2.0 \\
(1.0)\end{array}$ & $\begin{array}{l}3.6 \\
(1.2)\end{array}$ & $\begin{array}{l}3.6 \\
(1.2)\end{array}$ & $\begin{array}{l}3.6 \\
(1.3)^{\mathrm{a}}\end{array}$ & $\begin{array}{l}3.6 \\
(1.7)\end{array}$ & $\begin{array}{l}3.7 \\
(1.3)\end{array}$ & $\begin{array}{l}3.8 \\
(1.4)\end{array}$ & $\begin{array}{l}3.7 \\
(1.4)^{\mathrm{b}}\end{array}$ & \\
\hline Asia & $\begin{array}{l}2.0 \\
(0)\end{array}$ & $\begin{array}{l}2.8 \\
(1.2)\end{array}$ & $\begin{array}{l}3.6 \\
(1.5)\end{array}$ & $\begin{array}{l}2.9 \\
(1.2)\end{array}$ & 0 & $\begin{array}{l}2.7 \\
(1.0)\end{array}$ & $\begin{array}{l}4.1 \\
(1.6)\end{array}$ & $\begin{array}{l}3.2 \\
(1.3)^{\mathrm{a}}\end{array}$ & $\begin{array}{l}3.7 \\
(1.5)\end{array}$ & $\begin{array}{l}3.2 \\
(1.2)\end{array}$ & $\begin{array}{l}4.7 \\
(2.0)\end{array}$ & $\begin{array}{l}3.7 \\
(1.6)^{b}\end{array}$ & \\
\hline South America & 0 & $\begin{array}{l}3 \\
(1.4)\end{array}$ & 0 & $\begin{array}{l}3.0 \\
(1.4)\end{array}$ & 0 & $\begin{array}{l}4.1 \\
(0.8)\end{array}$ & $\begin{array}{l}4.5 \\
(1.3)\end{array}$ & $\begin{array}{l}4.2 \\
(0.9)^{\mathrm{b}}\end{array}$ & $\begin{array}{l}5.4 \\
(0.8)\end{array}$ & $\begin{array}{l}4.5 \\
(1.4)\end{array}$ & $\begin{array}{l}4.0 \\
(1.6)\end{array}$ & $\begin{array}{l}4.8 \\
(1.3)\end{array}$ & \\
\hline Africa & 0 & $\begin{array}{l}1.0 \\
(0)\end{array}$ & $\begin{array}{l}4.0 \\
(0)\end{array}$ & $\begin{array}{l}2.5 \\
(2.1)\end{array}$ & 0 & $\begin{array}{l}1.0 \\
(0)\end{array}$ & 0 & $\begin{array}{l}1.0 \\
(0)^{* *}\end{array}$ & 0 & $\begin{array}{l}2.8 \\
(0.4)\end{array}$ & $\begin{array}{l}2.0 \\
(0)\end{array}$ & $\begin{array}{l}2.7 \\
(0.5)^{\mathrm{a}}\end{array}$ & \\
\hline Oceania & $\begin{array}{l}3.0 \\
(0)\end{array}$ & $\begin{array}{l}1.3 \\
(0.5)\end{array}$ & $\begin{array}{l}1.0 \\
(0)\end{array}$ & $\begin{array}{l}1.5 \\
(0.9)\end{array}$ & 0 & $\begin{array}{l}4.0 \\
(1.4)\end{array}$ & $\begin{array}{l}3.0 \\
(1.7)\end{array}$ & $\begin{array}{l}3.4 \\
(1.5)^{\mathrm{b}}\end{array}$ & $\begin{array}{l}2.3 \\
(0.6)\end{array}$ & $\begin{array}{l}1.0 \\
(0)\end{array}$ & 0 & $\begin{array}{l}2.0 \\
(0.8)\end{array}$ & \\
\hline Total & $\begin{array}{l}3.0 \\
(1.2)\end{array}$ & $\begin{array}{l}2.9 \\
(1.4)\end{array}$ & $\begin{array}{l}3.0 \\
(1.9)\end{array}$ & $\begin{array}{l}2.9 \\
(1.5)\end{array}$ & $\begin{array}{l}2.5 \\
(1.6)\end{array}$ & $\begin{array}{l}3.1 \\
(1.3)\end{array}$ & $\begin{array}{l}3.8 \\
(1.4)\end{array}$ & $\begin{array}{l}3.2 \\
(1.4)\end{array}$ & $\begin{array}{l}3.7 \\
(1.5)\end{array}$ & $\begin{array}{l}3.3 \\
(1.4)\end{array}$ & $\begin{array}{l}4.0 \\
(1.6)\end{array}$ & $\begin{array}{l}3.6 \\
(1.5)\end{array}$ & $<.001^{*}$ \\
\hline$P$ & & & & .133 & & & & $<.001^{*}$ & & & & $<.001 *$ & \\
\hline
\end{tabular}

*Calculated using Kruskal-Wallis $(P<.05$ denotes significant difference)

**Africa was not included in comparison analysis due to its small sample size.

${ }^{a, b}$ Groups sharing same superscripted lowercase letters were not statistically different, according to Mann-Whitney U test $(P>.05)$. 
Table III. Authors' educational degrees by year, journal, and geographic origin

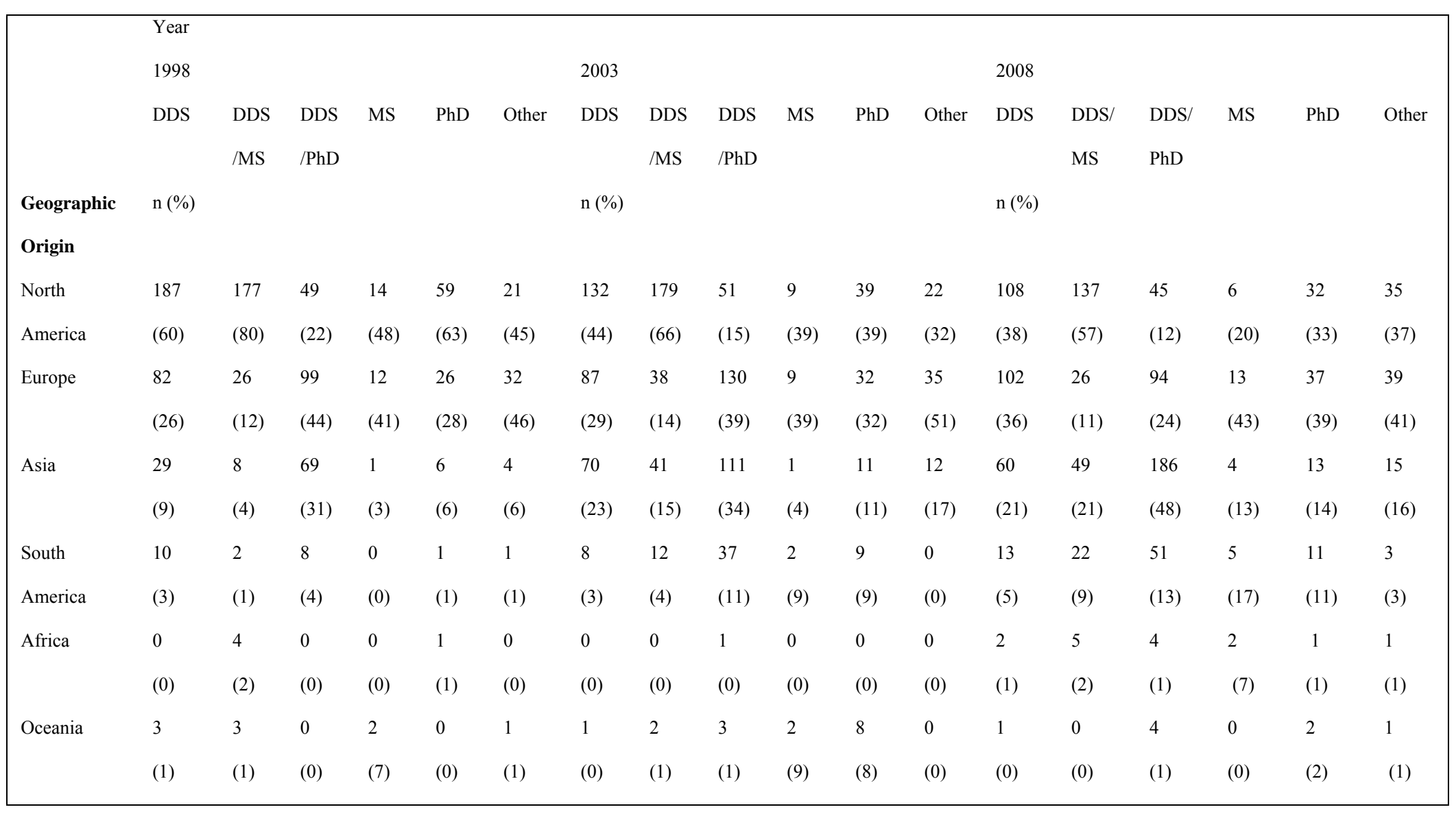


Table IV. Number of published articles and their geographic origin by year and by journal

\begin{tabular}{|llllllll|}
\hline Variables & $\begin{array}{l}\text { North } \\
\text { America }\end{array}$ & Europe & Asia & $\begin{array}{l}\text { South } \\
\text { America }\end{array}$ & Africa & Oceania & $P$ \\
Year & $\mathrm{n}(\%)$ & & & & & & \\
1998 & $184(55)$ & $93(28)$ & $41(12)$ & $8(3)$ & $2(1)$ & $6(2)$ & $<.001^{*}$ \\
2003 & $146(42)$ & $96(28)$ & $80(23)$ & $17(5)$ & $1(0)$ & $5(1)$ & \\
2008 & $112(35)$ & $85(27)$ & $90(28)$ & $22(7)$ & $6(2)$ & $4(1)$ & \\
Journal & $\mathrm{n}(\%)$ & & & & & & \\
JP & $102(59)$ & $24(14)$ & $32(19)$ & $10(6)$ & 0 & $4(2)$ & $<.001^{*}$ \\
JPD & $296(51)$ & $119(20)$ & $128(22)$ & $29(5)$ & $7(1)$ & $7(1)$ & \\
IJP & $44(18)$ & $131(55)$ & $51(21)$ & $8(3)$ & $2(1)$ & $4(2)$ & \\
\hline
\end{tabular}

${ }^{*}$ Calculated using Kruskal-Wallis $(P<.05$ denotes significant difference $)$ 


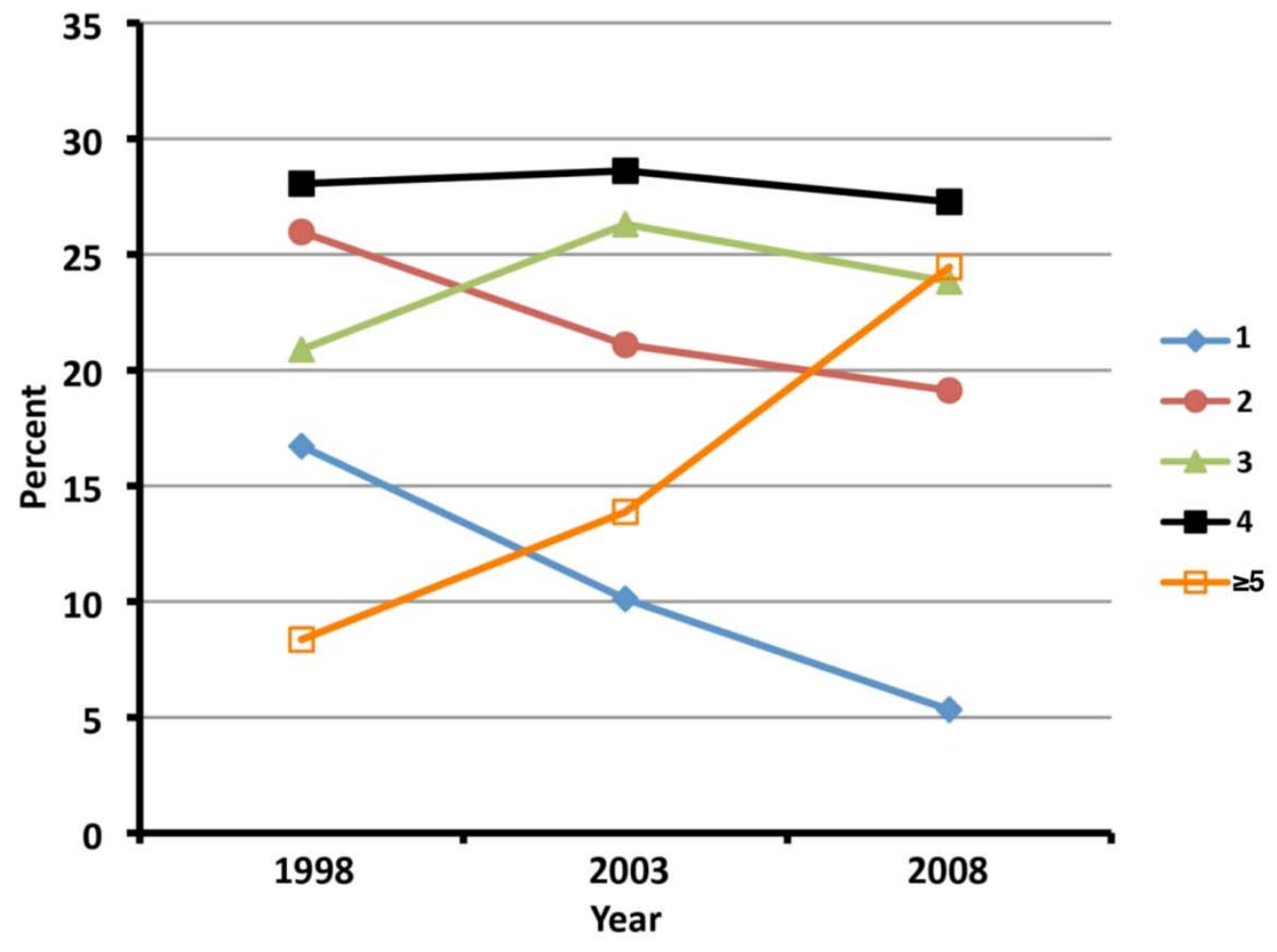

Figure 1. 


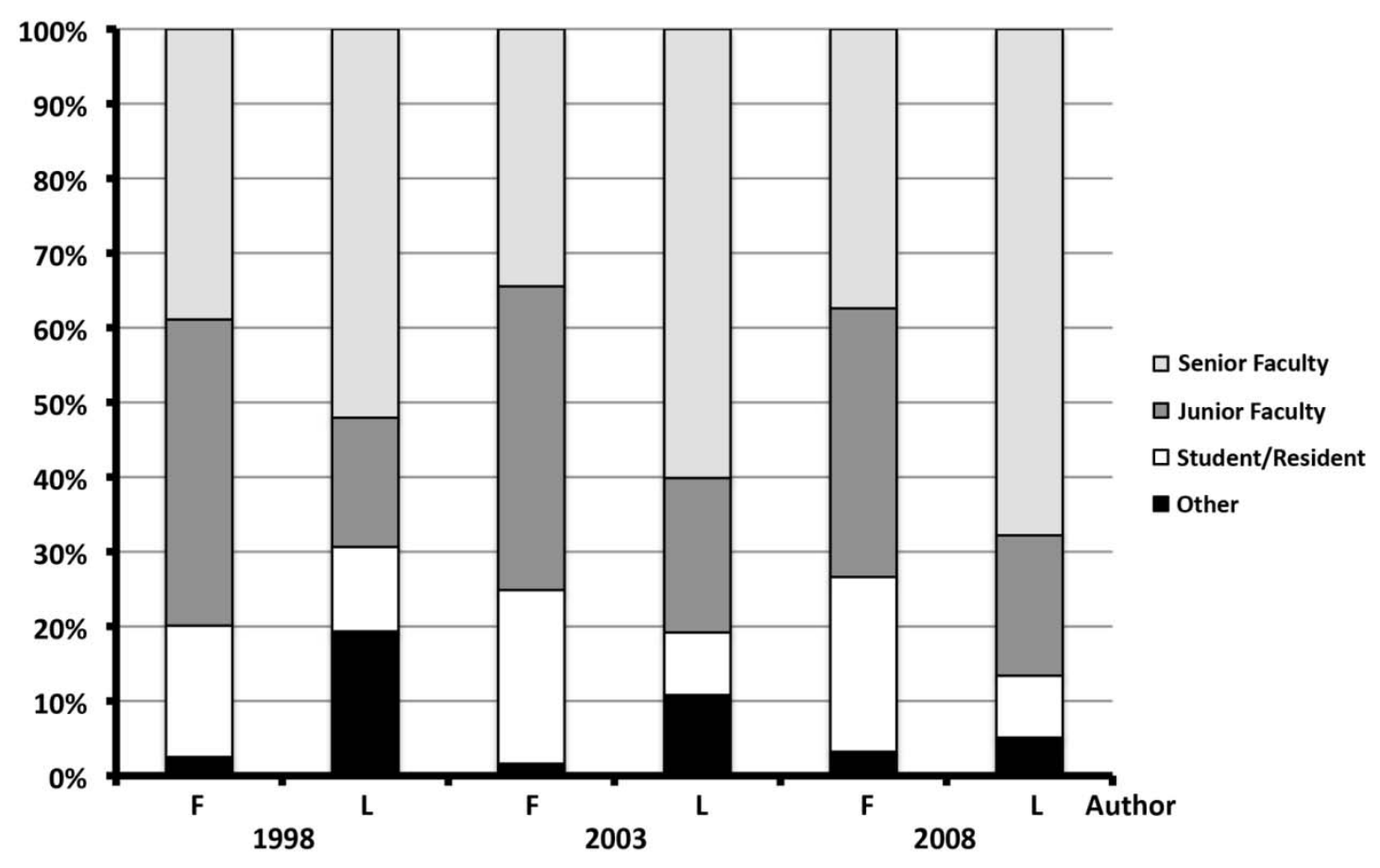

Figure 2. 


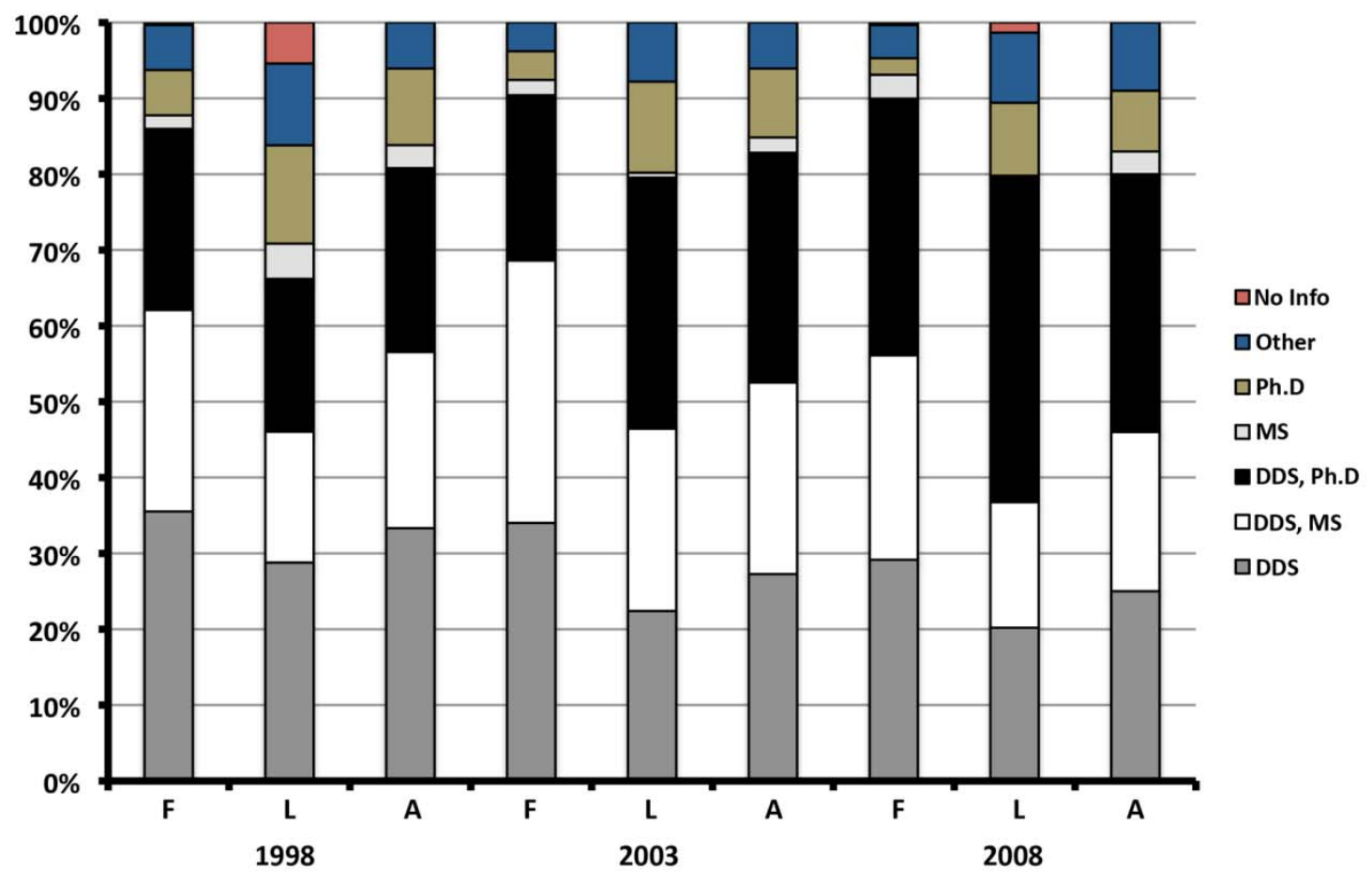

Figure 3. 


\section{LEGENDS}

Fig. 1. Prevalence of published articles having 1,2, 3, 4, and 5 or more authors per article over time.

Fig. 2. Proportion of academic ranks of first (F) and last (L) authors over time.

Fig. 3. Proportion of educational degrees of first (F), last (L), and all (A) authors over time. 